\title{
Shock Waves Analysis of the Novel Intake Design System for a Scramjet Propulsion
}

\author{
ABdulla Khamis AlHassani ${ }^{1}$, MOHANAD TAReK MOHAMED ${ }^{1}$, MOHAMmed FARES ${ }^{1}$, \\ SHARUL SHAM DOL ${ }^{1 *}$ \\ ${ }^{1}$ Department of Mechanical Engineering, Abu Dhabi University, Abu Dhabi, United Arab Emirates
}

\begin{abstract}
The supersonic combustion scramjet in the inlet applies the shock waves compression mechanism to substitute the actual compressor from a gas turbine engine. The scramjet works with combustion of fuel through the air stream in supersonic condition at least with Mach 5. Novel design of a scramjet intake system was made with variations in the angle of the fins and entrance width. The best combination of diameter and inclination angle was $1.75 \mathrm{~m}$ and 15 degrees, respectively. The findings were able to increase the oblique shock wave interactions and supplicate effective combustion and reduce pressure losses for the effective application of scramjet system.
\end{abstract}

Key-Words: - CFD; Compression; Density change; Intake; Mach number; Pressure loss; Scramjet; Shockwaves Received: November 27, 2020. Revised: March 23, 2021. Accepted: April 5, 2021. Published: April 13, 2021.

\section{Introduction}

With developments in hypersonic technologies, following in advancement with the ramjet engines, the scientists, aerodynamicists, and engineers motivated strongly towards the hypersonic or supersonic flight in the atmosphere [1]. The supersonic combustion ramjet or scramjet in the inlet uses the shock wave compression substituting the compression from gas turbine engine (Fig. 1). The ramjet works with combustion of fuel through the air stream moved in getting compressed by forward motion of the aircraft (instead of having fan blades like normal jet engine). The ramjet engine works at lower Mach number close to Mach 3. On the other hand, supersonic combustion ramjet (scramjet) intakes the airflow in supersonic condition at least with Mach 5 [2-3]. Scramjet is consisting of four components through the flow path including the inlet region, isolator, fuel injector, the combustor, and the nozzle region [1].

In the inlet region, the compression is achieved through the flow path however contains complex shock waves boundary layers and its interactions. The leading-edge geometry and compression inlet geometry of the channel affects the interactions of shock waves. Moving to the next section, combustion chamber, the mixing of the waves is intensive with turbulent mixing. With fuel injector, the diffusive combustion occurs, and huge amount of heat is generated with huge pressure disturbances (gradient) propagating upstream. To avoid any oscillatory back pressure, a special region as a buffer zone is kept before the combustors referred to 'isolator'. It is essential component through the flow path specially the inlet side of the isolator. The major role played by isolator is supplication of reduction in the back pressure that is built through the upstream flow in the combustion chamber. Hence, that isolator is placed between the inlet region and the region of combustion. The configuration of the injector and combustion chamber operation for ignition is also important in the design perspective and the last step of flow path through the nozzle is propulsion region where the thrust is gained [1].

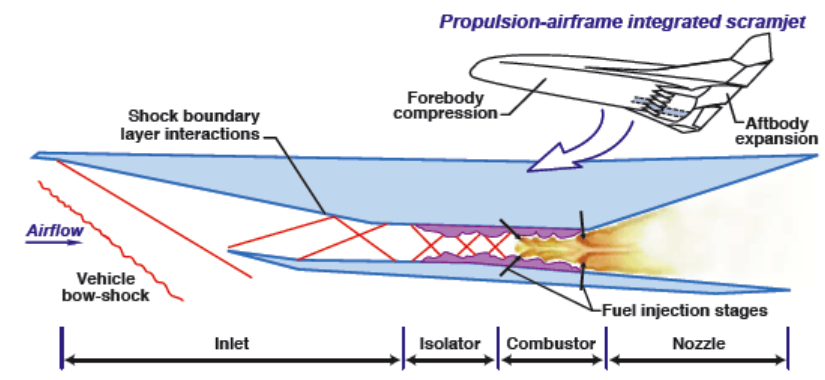

Figure 1: Scramjet propulsion [2]

In this project, there are two main objectives with the main goal is to minimize pressure losses by manipulating intake geometry to utilize a series of oblique shock waves, as the followings; 
1. To investigate the oblique shock wave interaction with the boundary layer at the intake.

2. To investigate conceptual design of intake to observe enhancement in efficiency.

\section{Literature Review}

Study conducted by Seleznev et al. [1] reviewed the experimental work on scramjets and discussed various experiments. The test conditions and geometry are also explained in the review. The experiment conducted to check the supersonic combustion through HIFiRE-2 consisted of smallscale testing with channel width of $10.16 \mathrm{~mm}$ and assisted with two injectors as shown in Figure 2. The tested conditions analysed two scenarios: the ground function and the flight function. These was due to the analysis difference when in flight function will faced shocks from inlet, and boundary layer and overall gas composition will be affected. Hence, the inlet geometry plays an important role in bringing about the effective performance of the combustor.

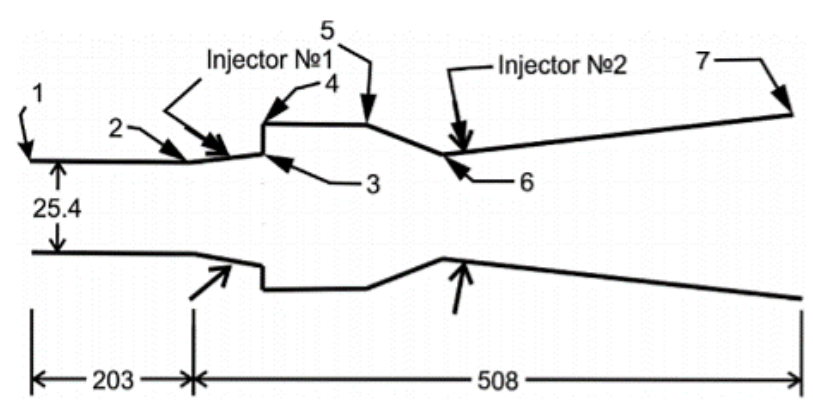

Figure 2: HIFiRE-2 Project Experimental Combustor Testing Geometry

As per the project conducted as the joint research efforts from NASA and CIAM - the Central Institute of Aviation Motors, Russia, the Scramjet flight testing program is named as 'Kholod' with focus on the inlet and the nozzle design. The inlet design is the inlet geometry as shown in Figure 3, it is consisting of inclined surfaces angled like 20,30, and 40 degrees with three stages [1].

The Mach number that was used in the Kholod experiment was 6.4 and the CFD analysis was also used along with experimental for validation. Another experiment conducted by CIAM under the name of 'Vinogradov' experiment, the full-scale geometry was tested with supersonic arrangement and the test section is shown below in Figure 4. It is consisting of fin like structures, now just inclinations, but also declinations. The angle of inclination is noted to be 30 degrees. The optimization of the flow conditions and the fuel injection ratio was successfully achieved through the Vinogradov experiment and useful data was integrated numerically to be used for coaxial scramjet simulations [1].

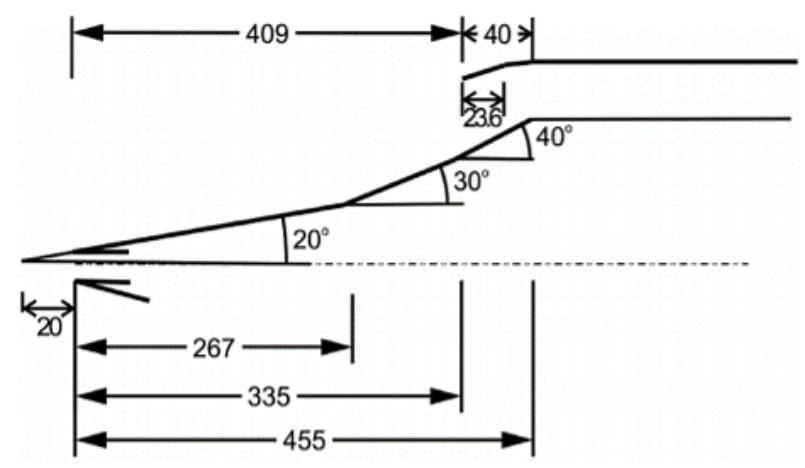

Figure 3: CIAM-NASA Project Scramjet Inlet Testing Geometry

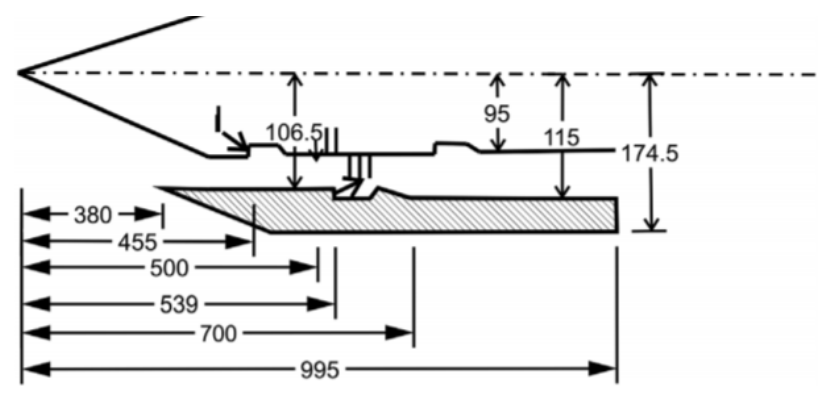

Figure 4: Vinogradov - CIAM Scramjet Inlet Test Geometry

A similar approach was adopted by University of Michigan in testing the two-mode operation of the scramjet and ramjet by including the isolator in the rectangular section and then combustor with cavity and then the nozzle. The channel width was kept as $25.4 \mathrm{~mm}$ and the nozzle width was kept as $38.1 \mathrm{~mm}$. In China, the CARDC - China Aerodynamics Research and Development Centre has created experimentation device with simple indentations to expansion nozzle. The Mach number used was 4.42 and the pressure inside the combustor was $0.82 \mathrm{~atm}$. The shock waves coming with high to low frequency pressure were found unsteady but were found to be in the relatively stable positions. The shock waves were found to be positioned with the leading edge. This was observed by the University of Virginia Supersonic Combustion Facility (UV-SCF) in 2008 [1]. The schematic of the test section is shown in Figure 5. It is consisting of the declination at 10 degrees and that is creating the edge leading to shock, which are essentially benefiting the combustion process and consequently improving the performance at the nozzle.

According to Smart [3], other flight programs that were tested recently with the supersonic combustion are HyShot-2 and Hyper-X flight programs with 
subscale testing. Apart from the experimental, the CFD analysis and its validation are also observed from literature. Study conducted by Shariatzadeh et al. [4], the scramjet testing for combustion is observed and at the throttle, the supersonic conditions are achieved as shown in Figure 6. ANSYS Fluent is used to analyse the flow conditions with a converging-diverging nozzle design.

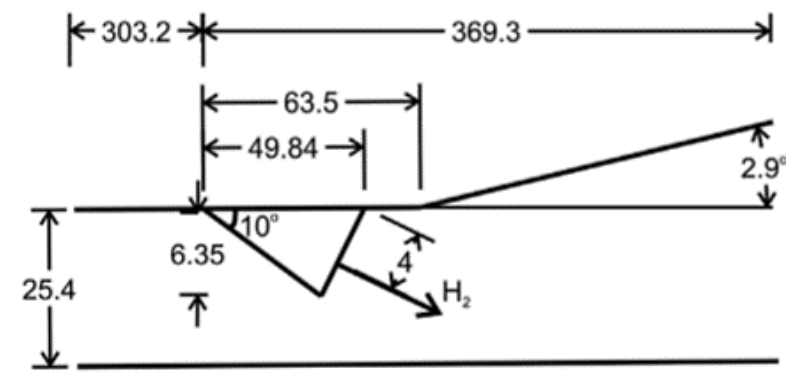

Figure 5: UV-SCF Combustion Testing Geometry
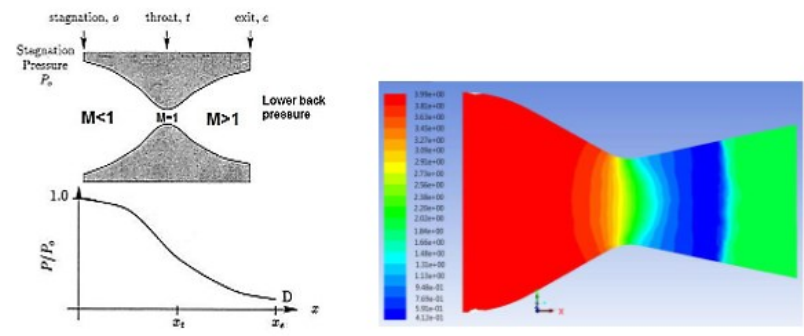

Figure 6: Converging-Diverging Geometry

The simulation results indicated that there CFD model was effective in predicting the supersonic flow across the geometry and the CFD calculation using different turbulence model either k-e model or the k$\omega$ model did not show significant impact on the tested results [5-7].

\section{Methodologies}

Figure 7 and 8 show the geometry of the design enhancements of the Scramjet intake section and its boundary conditions as well as meshing elements.

To analyse the scramjet design for better performance, the investigation of the oblique shock waves entering the inlet region of the scramjet are analysed. Moreover, the conceptual models are designed with variation in two parameters: the entrance width (the inlet diameter) and the angle of the fins. The fins are placed at the inlet entrance for enhancing the shock wave intake. The variations in these two parameters for angle 30 is analysed for the four cases (models): (1. Angle 30 and diameter 1.078 $\mathrm{m} ; 2$. Angle 30 and diameter $1.25 \mathrm{~m} ; 3$. Angle 30 and diameter $1.5 \mathrm{~m}$; 4. Angle 30 and diameter $1.75 \mathrm{~m}$ ) and variation for angle 15 is analysed for two cases (models) (1. Angle 15 and diameter $0.8 \mathrm{~m}$; and 2. Angle 15 and diameter $1.078 \mathrm{~m}$ ).

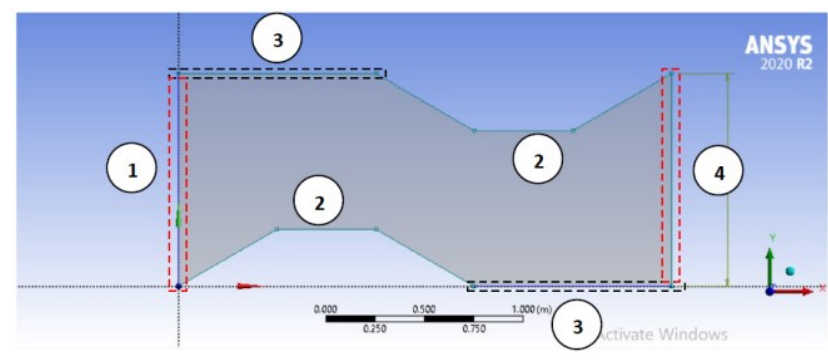

\section{Figure 7: Boundary Conditions of the Scramjet} Intake (Geometry)

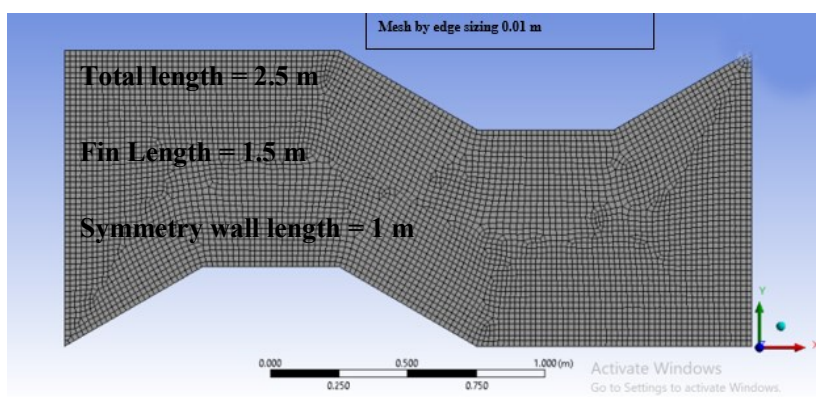

Figure 8: The Meshing Elements of the Geometry

Table 1: Boundary Conditions

\begin{tabular}{cccc}
\hline Location & Boundary Condition & Selection & Parameters \\
\hline $\mathbf{1}$ & Far-field & Pressure Far-field & $\begin{array}{c}\mathrm{P}_{\text {Gauge }}=54000 \mathrm{~Pa} \\
\text { Mach }=5 \\
\text { Temperature }=225 \mathrm{~K}\end{array}$ \\
\hline $\mathbf{2}$ & Fins & Walls & $\begin{array}{c}\text { Stationary Wall } \\
\text { No Slip }\end{array}$ \\
\hline $\mathbf{3}$ & Symmetry & Symmetry & - \\
\hline $\mathbf{4}$ & Outlet & Pressure Far-field & $\begin{array}{c}\mathrm{P}_{\text {Gauge }}=10000 \mathrm{~Pa} \\
\text { Mach }=0.9 \\
\end{array}$ \\
& & Temperature $=230 \mathrm{~K}$ \\
\end{tabular}

Simulation using the ANSYS software with its fluent module is used to model the scramjet inlet conceptual designs. The flow entering the scramjet is observed at Mach number of 5 and the flow that is passed the fin regions is assumed to 0.9 Mach number. The pressure far field is kept $54 \mathrm{kPa}$ and other boundary conditions are shown in Table 1 (please also refer to Fig. 7). These assumptions are based on the flow conditions of the scramjet and required Mach number for combustion region. The model is solved using the density-based solver because the flow is compressible. With steady-state analysis, the air is selected as the flow fluid and that is operating at zerogauge pressure. The activated equations are 'energy equations', and turbulence model responsible for flow variation - $\mathrm{k}-e$ model is activated with scalable wall functions. The use of k-e model or the $k-\omega$ 
model did not show significant impact on the tested results according to Shariatzadeh et al. [4]. The solutions methods are all kept second order for better accuracy. The residual monitors were kept $10^{-5}$ and calculations were run for 1000 iterations. In the post processor, the 'results' are plotted as contours of density (magnitude), static pressure, and velocity. The shock waves are then observed and consequently the other parameters are changed.

\section{Analysis and Results}

The analysis of this case $\left(A=30^{\circ}\right.$ and $\left.D=1.078 \mathrm{~m}\right)$ shows that the shock waves are developing with inclination of the fin wall (Fig. 9-11). Based on the allowed width for the supersonic flow, the shock wave interaction at the top is observed to be normal shocks. The developing shock wave from the bottom fin surface is oblique shock wave and it is the one that is expected to be carried to the inner section. As it is observed the interaction leading to the inside is making the oblique shock wave at higher inclinations, the oblique wave is becoming toward normal. This is undesirable. Hence, the decision was to increase the diameter of the entrance region. The density contour is very clearly providing the overview of the developing shock waves, whereas the pressure and the velocity contours show the interaction of the shock waves in clear manner [8].

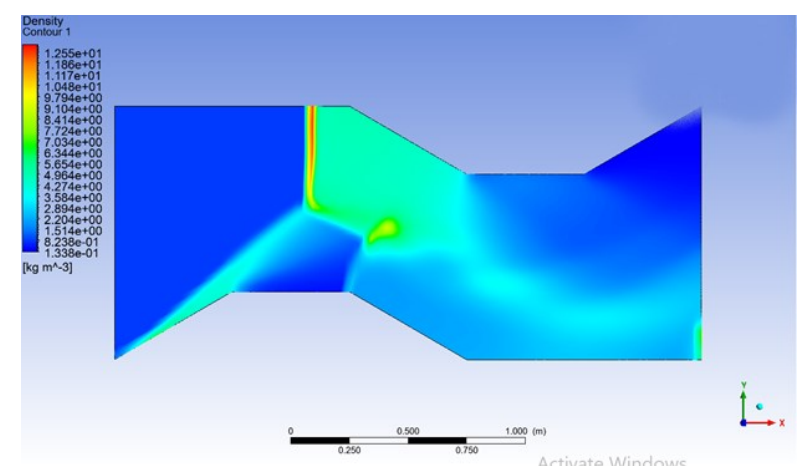

Figure 9: Density Contours $\left(A=30^{\circ}\right.$ and $D=$ $1.078 \mathrm{~m})$

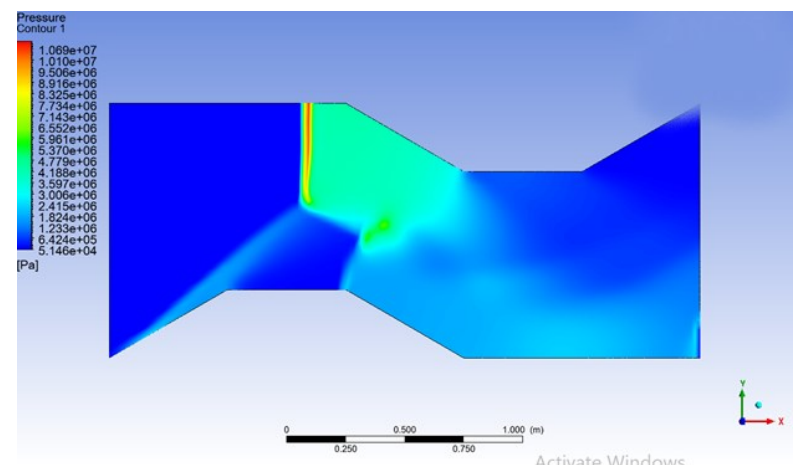

Figure 10: Pressure Contours $\left(A=30^{\circ}\right.$ and $D=$ $1.078 \mathrm{~m})$

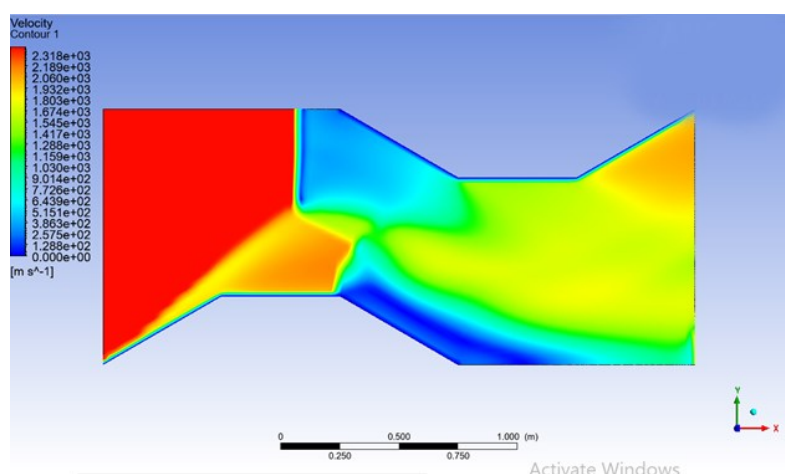

Figure 11: Velocity Contours $\left(A=30^{\circ}\right.$ and $D=$ $1.078 \mathrm{~m})$

For the next case, the diameter is increased to $1.25 \mathrm{~m}$ and the simulation is run again. There is an improvement in the development of oblique shock waves observed from $\left(A=30^{\circ}\right.$ and $\left.D=1.078 \mathrm{~m}\right)$ to case $\left(A=30^{\circ}\right.$ and $\left.D=1.25 \mathrm{~m}\right)$ as shown in Fig. $12-$ 14. The shock waves that were developing normal from the top have also move a bit right. Moreover, the shockwave interactions have observed to be more effective as the variation in the density and pressure is observed high in the centre region. Hence, the decision was taken for increasing the diameter of the inlet intake channel to $1.5 \mathrm{~m}$ (Fig. 15-17) and $1.75 \mathrm{~m}$ (Fig. 18-20). The observations are noted in the next section.

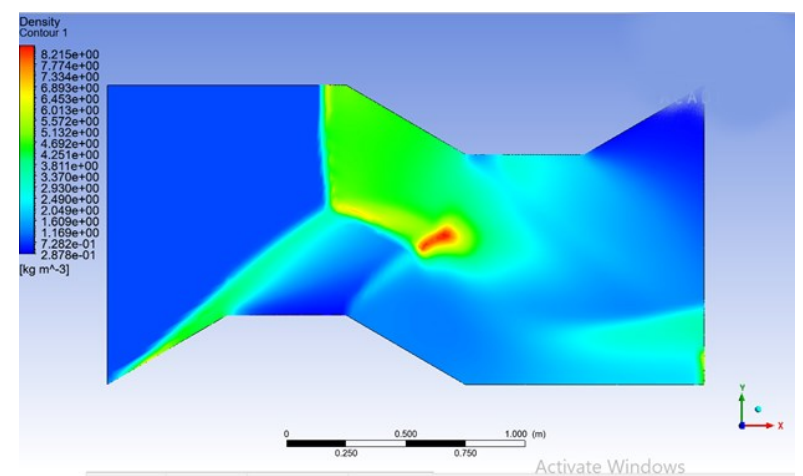

Figure 12: Density Contours $\left(A=30^{\circ}\right.$ and $D=$ $1.25 \mathrm{~m})$

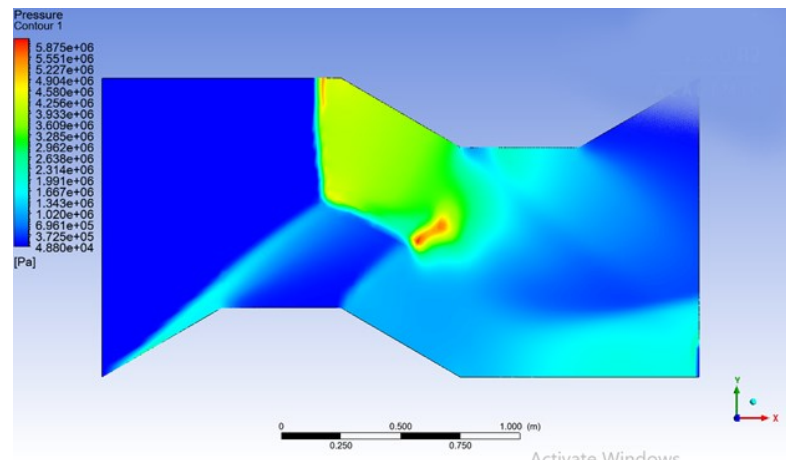

Figure 13: Pressure Contours $\left(A=30^{\circ}\right.$ and $D=$ $1.25 \mathrm{~m})$ 


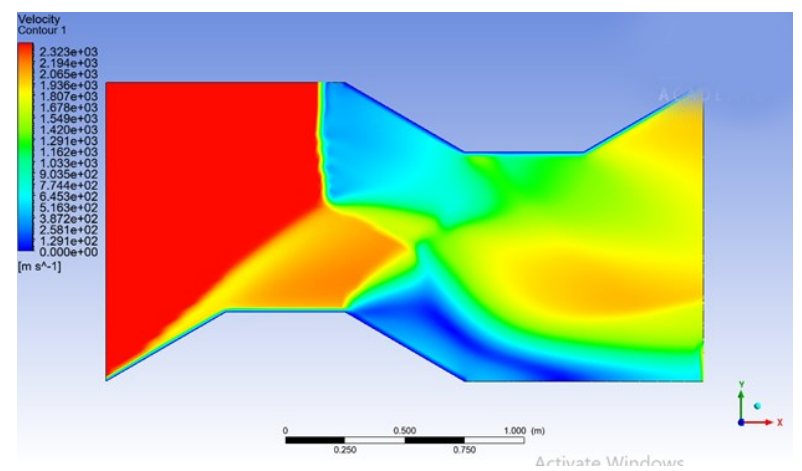

Figure 14: Velocity Contours $\left(A=30^{\circ}\right.$ and $D=$ $1.25 \mathrm{~m})$

A significant improvement in the development of the oblique shock waves is observed from the density and pressure contours (Fig. 15-16). Further, the top shock wave is now fully shifted from the normal to oblique behaviour. The boundary layer interactions are effective shown from the velocity contour and there are many shock waves entering the region from left to right supplicated to the combustor (Fig. 17). This is expected to improve the system performance [912].

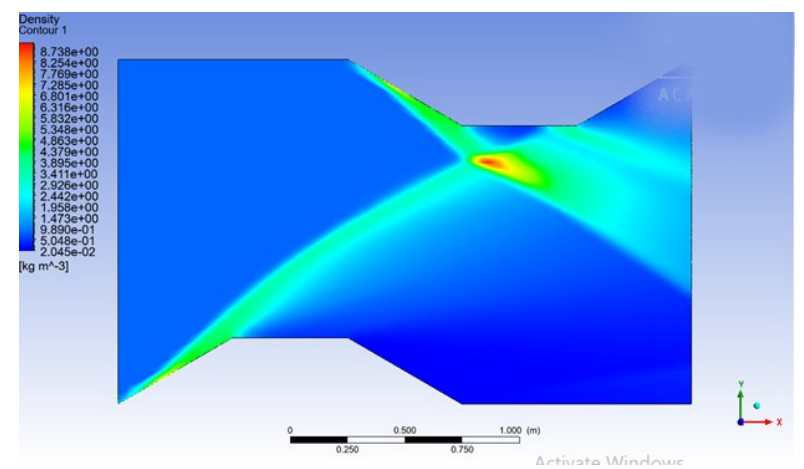

Figure 15: Density Contours $\left(A=30^{\circ}\right.$ and $D=1.5$ m)

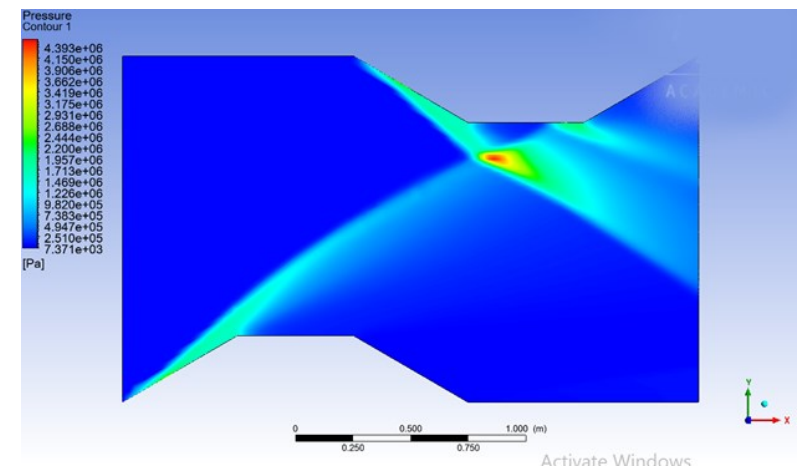

Figure 16: Pressure Contours $\left(A=30^{\circ}\right.$ and $D=$ $1.5 \mathrm{~m})$

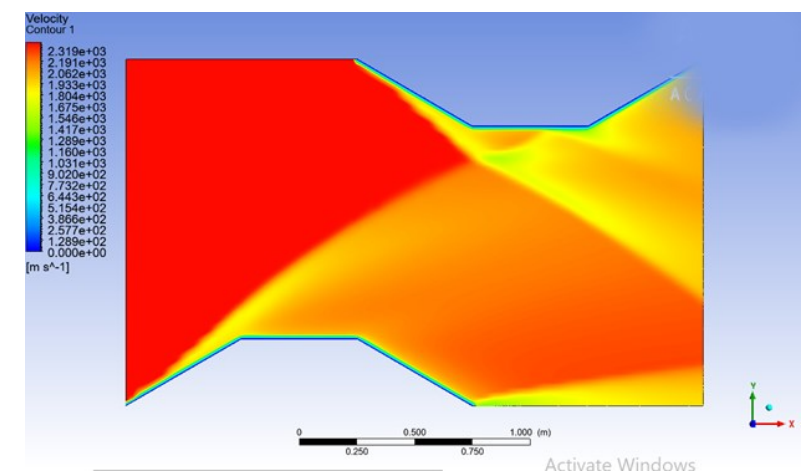

Figure 17: Velocity Contours $\left(A=30^{\circ}\right.$ and $D=$ $1.5 \mathrm{~m})$

A similar significant improvement in the development of the oblique shock waves is observed from the density and pressure contours (Fig. 18-19). Further, the top shock boundary layer development is stable to more oblique behaviour. The boundary layer interactions are effective shown from the velocity contour and there are many shock waves entering the region from left to right supplicated to the combustor (Fig. 20). This is expected to improve the system performance [13-14]. Hence, both cases are selected for the 30 degrees fin inclination analysis.

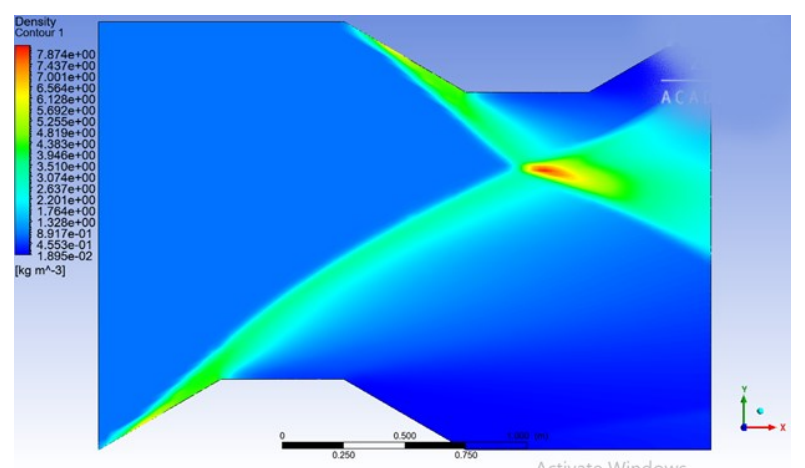

Figure 18: Density Contours $\left(A=30^{\circ}\right.$ and $D=$ $1.75 \mathrm{~m})$

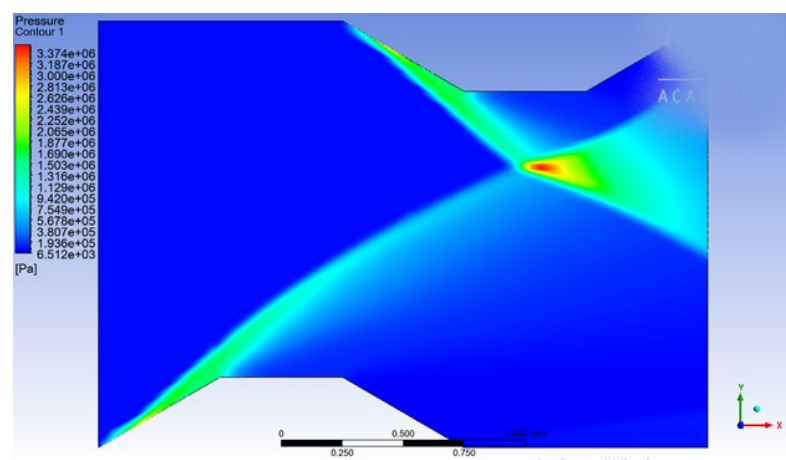

Figure 19: Pressure Contours $\left(A=30^{\circ}\right.$ and $D=$ $1.75 \mathrm{~m}$ ) 


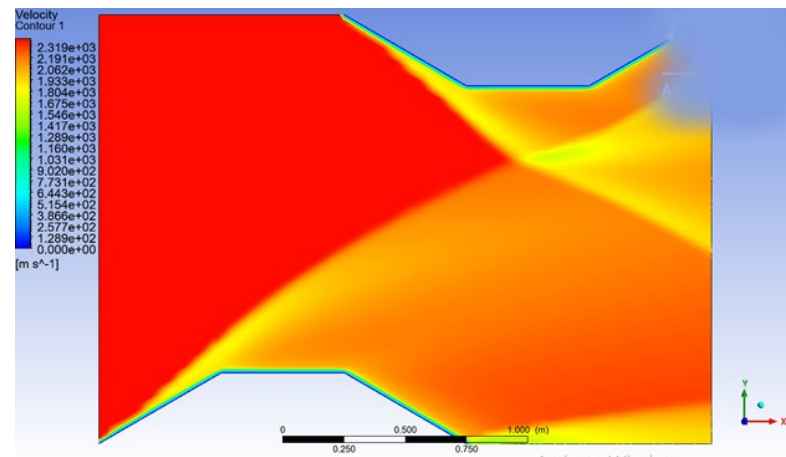

Figure 20: Velocity Contours $\left(A=30^{\circ}\right.$ and $D=$ $1.75 \mathrm{~m})$

Now, observing the cases related to fin inclination with 15 degrees in the next section (Fig. 21-26). The illustrations show that from decreasing the inclination angle from 30 degrees to 15 degrees, sharp oblique waves are observed (Fig. 21-23). Further, the case $\left(A=15^{\circ}\right.$ and $\left.D=1.078 \mathrm{~m}\right)$ shows that density distribution variation is average in the beginning on the inlet region and then it is highly concentration in the throttle region and the pressure as well creating the oblique shock wave interaction moving toward the inside. Now, for the next case, the channel width is decreased to $0.8 \mathrm{~m}$ and observed the simulation results (Fig. 24-26).

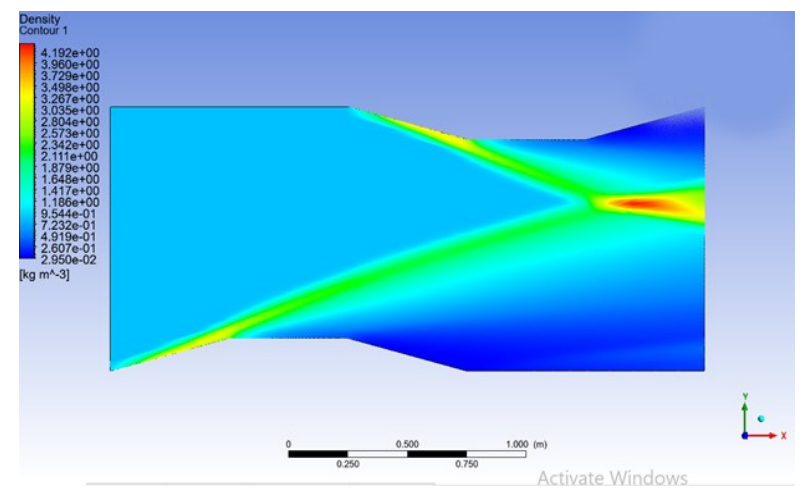

Figure 21: Density Contours $\left(A=15^{\circ}\right.$ and $D=$ $1.078 \mathrm{~m})$

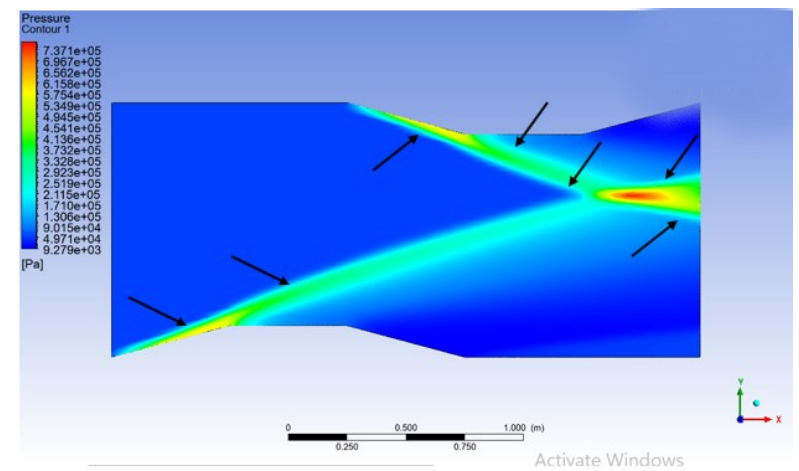

Figure 22: Pressure Contours $\left(A=15^{\circ}\right.$ and $D=$ $1.078 \mathrm{~m})$

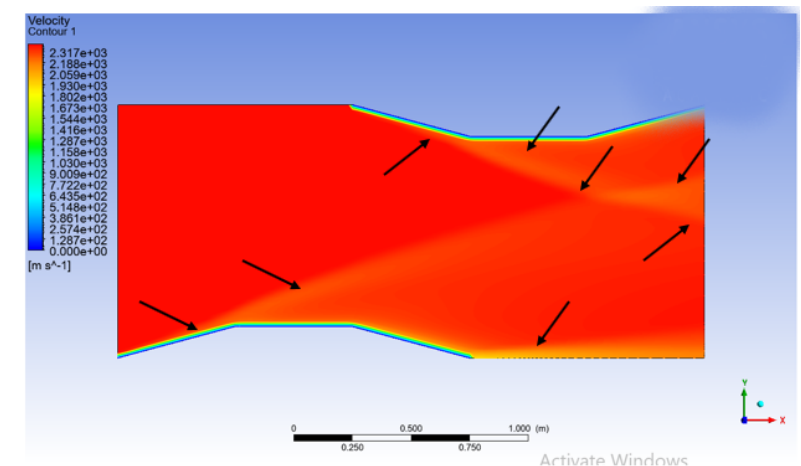

Figure 23: Velocity Contours $\left(A=15^{\circ}\right.$ and $D=$ $1.078 \mathrm{~m})$

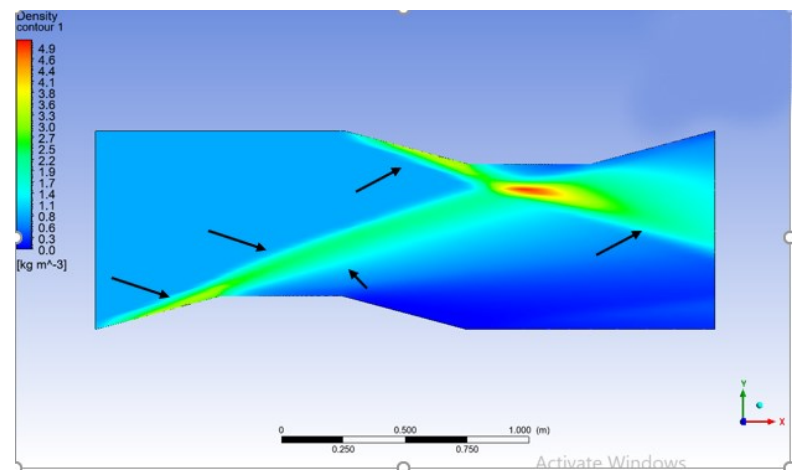

Figure 24: Density Contours $\left(A=15^{\circ}\right.$ and $D=0.8$ m)

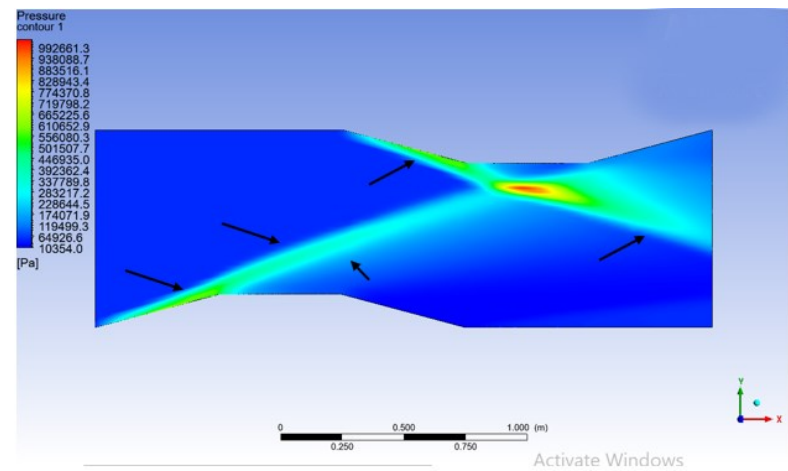

Figure 25: Pressure Contours $\left(A=15^{\circ}\right.$ and $D=$ $0.8 \mathrm{~m})$

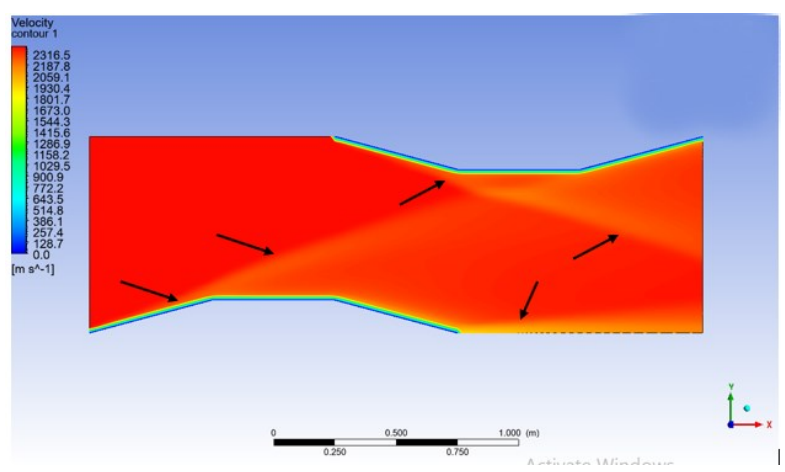

Figure 26: Velocity Contours $\left(A=15^{\circ}\right.$ and $D=$ $0.8 \mathrm{~m}$ ) 
The results indicate that the oblique shock waves were much better and boundary interactions was effective [15-18]. The pressure variations also show the impact as in the first case the maximum pressure inside was less.

\section{Findings and Discussion}

The main findings of the CFD analysis are as follows:

- The variation in the parameter (channel width) have shown that oblique waves that are generated at the inlet and enter the scramjet isolator or combustor region are increasing with increasing channel width.

- The variation in the parameter (fin shape inclination angle) have shown that oblique waves that are generated at the inlet and enter the scramjet isolator or combustor region are increasing with decreasing inclination angle [1920].

- It can be deduced that the best combination of diameter and inclination angle is $1.75 \mathrm{~m}$ and 15 degrees, respectively.

From literature, the oblique shock waves are desired from inlet fins moving towards the inside region towards the combustor. It is also observed that fins are made before or after the combustor to increase the oblique shock wave interaction and supplicate effective combustion and reduce pressure losses [21$22]$. Next, the data will be validated by the means of experiments [23-26].

\section{Conclusion}

All to sum up, studying the scramjet operations through experiments can be expensive and can take lot of resources. Using CFD, the initial analysis can be done and then in this manner the small-scale testing can be done through experimental setup. The main findings show that variation in the parameter (channel width) have shown that oblique waves are increasing with increasing channel width. On other hand, variation in the fin shape inclination angle have shown that oblique waves are increasing with decreasing inclination angle.

\section{References}

[1] R. Seleznev, S. Surzhikov and J. Shang, "A review of the scramjet experimental data base," Progress in Aerospace Sciences, vol. 106, pp. 43-70, 2019.

[2] Nasa, "How Scramjets Work," 2006. [Online]. Available: https://www.nasa.gov/centers/langley/news/f
actsheets/X43A_2006_5.html\#: :text=A\%20 scramjet $\% 20$ (supersonic $\% 2$ Dcombustion $\% 2$ 0ramjet,to $\% 20$ at $\% 201$ east $\% 20$ Mach $\% 2015$.

[3] M. Smart, "Scramjets," The Aeronautical Journal, vol. 111, no. 1124, pp. 605-619, 2007.

[4] O. J. Shariatzadeh, A. Abrishamkar and A. J. Jafari, "Computational Modeling of a Typical Supersonic Converging-Diverging Nozzle and Validation by Real Measured Data," Journal of Clean Energy Technologies, vol. 3, no. 3, pp. 220-225, 2015.

[5] DOL, Sharul Sham; CHAN, Hiang Bin; WEE, Siaw Khur. FSI SIMULATION OF A FLEXIBLE VORTEX GENERATOR AND THE EFFECTS OF VORTICES TO THE HEAT TRANSFER PROCESS. Platform : A Journal of Engineering, [S.1.], v. 4, n. 2, p. 5869, June 2020.

[6] Sharul Sham Dol, Chan Hiang Bin. "FluidStructural Interaction Simulation of Vortices behind a Flexible Vortex Generator." 2019 8th International Conference on Modeling Simulation and Applied Optimization (ICMSAO), pp. 1-5. IEEE, 2019.

[7] Hiang Bin Chan, Tshun Howe Yong, Perumal Kumar, Siaw Khur Wee, Sharul Sham Dol. "The Numerical Investigation on the Effects of Aspect Ratio and Cross-Sectional Shape on the Wake Structure behind a Cantilever". ARPN Journal of Engineering and Applied Sciences, vol. 11, no. 16, pp. 9922-9932, 2016.

[8] M. O. Khan, M. A. Khan and S. S. Dol, "Effects of Chevrons on the Acoustic Noise and Velocity Patterns of Aircraft Nozzles," 2020 International Conference on Decision Aid Sciences and Application (DASA), Sakheer, Bahrain, 2020, pp. 845-849.

[9] Abdul Qader Hasan, Nasr M. Al-Khudhiri, Muhammad A. Iqbal, Sharul Sham Dol, Abid Abdul Azeez, Mohamed S. Gadala, "Aerodynamics Analysis on Wings with Winglets and Vortex Generators", WSEAS TRANSACTIONS ON FLUID MECHANICS, 15, pp. 193-201, 2020.

[10] Sharul S. Dol. "Weakened Vortex Shedding from a Rotating Cylinder." International Journal of Mechanical and Mechatronics 
Engineering, vol. 7, no. 10, pp. 2013-2020, 2013.

[11] Sharul S. Dol, U. Azimov and Robert J. Martinuzzi. "Statistical description in the turbulent near wake of rotating circular cylinder". International Journal of Mechanical, Aerospace, Industrial, Mechatronic and Manufacturing Engineering, vol. 6, no. 12, pp. 2706-2710, 2012.

[12] Sharul S. Dol and Robert J. Martinuzzi. Patterns of vortex shedding from a rotating cylinder. Proceedings of 7th CUTSE International Conference. Curtin University, Sarawak, 2012.

[13] S.S. Dol. Image analysis of the vortex shedding of stationary and rotating circular cylinder. Proceedings of the Eleventh Asian Congress of Fluid Mechanics. Kuala Lumpur, Malaysia, 2006.

[14] Sham, S., Martinuzzi, R.J. and Kopp, G.A. "Suppression of period vortex shedding in the wake of rotating circular cylinder". Proceedings of the 5th International Colloquium on Bluff Body Aerodynamics and Applications. Ottawa, Canada, 2004.

[15] Sharul Sham Dol, Hiang Bin Chan, Siaw Khur Wee, Kumar Perumal. "The effects of flexible vortex generator on the wake structures for improving turbulence." IOP Conference Series: Materials Science and Engineering, vol. 715, no. 1, p. 012070. IOP Publishing, 2020.

[16] Siew Fan Wong, Sharul Sham Dol, "Turbulence Characteristics Study of the Emulsified Flow", WSEAS TRANSACTIONS ON HEAT AND MASS TRANSFER, 14, pp. 45-50, 2019.

[17] Sharul Sham Dol, Siaw Khur Wee, Hiang Bin Chan, Perumal Kumar, "Turbulence Characteristics behind a Flexible Vortex Generator", WSEAS TRANSACTIONS ON FLUID MECHANICS, 14, pp. 1-7, 2019.

[18] Yong, T. H., H. B. Chan, S. S. Dol, S. K. Wee, and P. Kumar. "The flow dynamics behind a flexible finite cylinder as a flexible agitator." In IOP Conference Series: Materials Science and Engineering, vol. 206, no. 1, p. 012033. IOP Publishing, 2017.

[19] Sharul Sham Dol. "Proper orthogonal decomposition analysis of vortex shedding behind a rotating circular cylinder". EPJ Web of Conferences, vol. 114, 02019, 2016.

[20] Sharul S. Dol, Mehdi M. Salek and Robert J. Martinuzzi. "Energy Redistribution between the Mean and Pulsating Flow Field in a Separated Flow Region". ASME Journal of Fluids Engineering, vol. 136(11): 111105, 2014.

[21] SF Wong, SS Dol. "Simulation Study on Vehicle Drag Reduction by Surface Dimples". International Journal of Mechanical, Aerospace, Industrial, Mechatronic and Manufacturing Engineering, vol. 10, no. 3, pp. 560-565, 2016.

[22] CK Chear, SS Dol. "Vehicle Aerodynamics: Drag Reduction by Surface Dimples." International Journal of Mechanical, Aerospace, Industrial and Mechatronics, vol. 9, no. 1, pp. 202-205, 2015.

[23] TH Yong, SS Dol. "Design and Development of Low-Cost Wind Tunnel for Educational Purpose". IOP Conference Series: Materials Science and Engineering, 78, 012039, 2015.

[24] Sharul Sham Dol, Mohd Arief Mohd Nor and Muhamad Khairun Kamaruzaman. "Flow visualization of the vortex shedding of a stationary circular cylinder by an improved smoke-wire technique". WSEAS Transactions on Fluid Mechanics, Issue 6, Volume 1, pp.745-752, 2006.

[25] Sharul Sham Dol, Mohd Arief Mohd Nor and Muhamad Khairun Kamaruzaman. "An improved smoke-wire flow visualization technique". Proceedings of the 4th WSEAS International Conference on Fluid Mechanics and Aerodynamics, Elounda, Greece, August 21-23, pp. 231-236, 2006.

[26] Zahari, M. A., and S. S. Dol. "Effects of different sizes of cylinder diameter on vortexinduced vibration for energy generation." Journal of Applied Sciences 15, no. 5 (2015): 783-791 


\section{Creative Commons Attribution License 4.0 (Attribution 4.0 International, CC BY 4.0)}

This article is published under the terms of the Creative Commons Attribution License 4.0

https://creativecommons.org/licenses/by/4.0/deed.en_US 